\title{
Televisão: das lógicas às configurações discursivas
}

Elizabeth Bastos Duarte Universidade do Vale do Rio dos Sinos/UNISINOS 


\section{Resumo}

Uma investigação sobre os sentidos da produção televisiva enquanto texto, que considere suas condições de uso, seu trajeto nos circuitos de sentido, seu reinvestimento nas redes de sociabilidade, deve levar em conta essa relação entre lógicas, estratégias comunicativas e discursivas e configurações discursivas produzidas. $\mathrm{O}$ trabalho propõe-se refletir sobre essa articulação entre as diferentes lógicas que presidem os processos de produção, circulação e consumo dos produtos midiáticos, as estratégias comunicativas e discursivas delas decorrentes, bem como as configurações discursivas através das quais essas estratégias se manifestam em textos-programas "informativos"(talk-shows, telejornais, magazines): as figuras.

\section{Palavras-chave}

lógicas, estratégias, configurações

\section{Abstract}

An investigation of the meanings of television programs as texts, when considering their uses, their circulation among meaning circuits, their re-investment in the sociable networks, must consider the relationship amongst logics, communication and discourse strategies and the produced discourse configurations. This work aims to think about this arrangement of the various logics which organise production, circulation and consumption of mediatic artefacts; the communicative and discoursive strategies that follow from it and, also, the discourse configurations through which these strategies manifest themselves in 'informative' text-programs (talk-shows, news programs, variety shows): the figures.

\section{Key words}

logics, strategies, configurations 
ivemos o incrível privilégio de estar ligados à mídia, o que significa para o homem contemporâneo a possibilidade de participação de um tempo histórico, de acesso às mais diversas experiências de realidade, informação, comunicação, de ruptura com barreiras de tempo e espaço, de superação dos sentidos.

Mas, se as mídias, como instrumentos prodigiosos que são, convertem o mundo em fatos imediatamente acessíveis ao cotidiano planetário, elas, ao fazerem isso, não só pautam o que é realidade, como reduzem, como não poderia deixar de ser, essa realidade ao discurso, construído na inter-relação de diferentes sistemas intersemióticos e intermidiáticos. $\mathrm{E}$, em que pese a frustração de tamanha redução, penso que somente aceitando o caráter inequivocadamente discursivo das mídias, torna-se possível avançar um pouco mais em direção a questões polêmicas que vêm ocupando espaço no debate em torno dos mass media.

Para desenvolver algumas reflexões a esse respeito, centro minha atenção, neste trabalho, em particular na televisão, mais especificamente, na produção televisiva ligada à apresentação do "real". Seria aquilo que muitos denominam de televisão "factual" ou televerdade e dirige-se a determinadas estratégias e configurações instauradas na comunicação televisual, com vistas à restituição e oferta de "realidade" ao espectador.

Mas que "verdade" ou "realidade" pode pretender a televisão? Essa é uma primeira questão que vale a pena retomar pelo seu caráter polêmico: a consideração da tevê, não apenas pela sua função experimental de extensão dos sentidos, tampouco pela sua capacidade manipulatória, mas, e essencialmente, pela sua força de constituição, de geração do real. 
Nessa perspectiva, não obstante, é preciso lembrar que se padece da nostalgia do que nunca se teve. Sempre existiu uma realidade para aquém e para além, apesar das linguagens e hoje, das mídias. Mas o fato de o pensamento humano recorrer aos signos, de a cultura constituir-se em um emaranhado de sistemas simbólicos e de as linguagens serem elementos de mediação e expressão dessas representações, desde sempre decretaram a impossibilidade de acesso direto à realidade. As mídias apenas acrescentam novos e diferentes empecilhos a esse "acesso", recursos mais sofisticados que são na construção/representação dessa realidade.

Veja-se o caso da televisão: mesmo que sua maior potencialidade seja poder realizar a transmissão direta, em tempo real; mesmo que toda a transmissão contenha em si a possibilidade de "imprevisto", está sempre presente, em qualquer um dos produtos televisivos, seu caráter de mediatização. Afinal, os textos-programa não são o real. O mundo se nos apresenta por todos os sentidos; no texto televisivo, somente algumas desšas propriedades são transpostas para a superfície artificial do vídeo. A alteração de cores, a mudança de dimensões, a ausência de cheiro, de temperatura constituem-se numa redução muito grande dos atributos do mundo representado, pois, a rigor, somente os traços sonoros e visuais são imitados, e tais traços, assim selecionados e transpostos, pouco representam em relação à riqueza do mundo material: são figuras, não objetos do mundo. Além disso, as parcelas de real não correspondem a seleções arbitrárias: é o que fica enquadrado, é o movimento das câmeras que determina o que vai ser mostrado. A isso se acrescenta todo um trabalho de edição, de sonoplastia etc...

Assim, o próprio meio desempenha funções na construção desses produtos: a televisão passa a funcionar como uma linguagem que sobredetermina outras linguagens sonoras e visuais, submetendo-as às regras da gramática televisiva, respeitadas tanto pela instância de emissão, como pela de recepção.

O recente e trágico atentado terrorista de setembro/2001 é um bom exemplo da utilização dessas regras. Sua grande particularidade foi ter sido estrategicamente planejado considerando essa gramática; seus tempos e espaços foram acertados para corresponder às etapas de construção do simulacro televisivo. 
O que confere complexidade à enunciação televisiva é o fato de que, para a tessitura de seus textos-programa, concorrem relações de duas ordens, intersemiótica e intermidiática: de um lado, o texto televisivo articula enunciações do "mundo natural", com suas próprias regras, àquela, cuja colocação em discurso se deve ao aparato televisivo, encarregado de identificar e transmitir o acontecimento; de outro, esse texto se relaciona com outros, produzidos pela própria televisão e/ou por outras mídias.

Assim, embora, grande parte das transmissões diretas trabalhe com elementos que já se constituem em matéria significante, 0 processo de dotá-los de uma nova forma de expressão, significa também a atribuição de novos conteúdos, principalmente porque a produção televisiva é presidida por um complexo de lógicas, porque atende a muitos senhores. E essa é uma segunda questão a levantar: o papel da articulação dessas diferentes lógicas na construção do texto televisivo.

Uma investigação sobre a produção televisiva em sua textualidade, que considere suas condições de uso, seu trajeto nos circuitos de sentido, seu reinvestimento nas redes de sociabilidade, deve levar em conta a relação entre as lógicas que presidem a produção desses produtos, as estratégias comunicativas e discursivas empregadas para sua enunciação e as configurações discursivas produzidas.

Nessa direção, acredita-se que, para pensar a produção televisiva, é necessário primeiramente tensionar as diferentes lógicas que presidem a enunciação dos produtos televisivos. Por lógicas, aqui se entende um conjunto de categorias racionalizáveis que direcionam as deliberações e interferem na escolha das operações comunicativas e discursivas empreendidas na produção de um determinado texto-programa. Lógicas são, pois, racionalidades (razões, causas, argumentos, justificativas) de diferentes ordens (econômica, tecnológica, simbólica, pedagógica) que interferem nas escolhas discursivas e definem as funções (finalidades) dos atos comunicativos. A mídia televisão, como suporte organizacional que é, procura integrar essas diferentes lógicas, algumas delas constantes, tais como a econômica, que diz respeito ao seu estatuto de empresa; a 
tecnológica, que remete à qualidade e a quantidade de sua difusão, isto é, aos meios técnicos de produção, circulação e consumo de seus produtos; a discursiva, que trata da maneira como os produtos televisivos, que são produtos discursivos, se estruturam regulando as trocas sociais e construindo as representações que os homens fazem dos valores subjacentes às suas práticas, criando e manipulando signos e assim produzindo sentidos; e outras, de caráter mais variável, da ordem dos aspectos situacionais ou individuais.

Ninguém há de negar, por exemplo, o papel dos meios de comunicação e da televisão, em particular, na legitimação das operações bélicas desencadeadas a partir do ataque terrorista de 11 de setembro aos EUA. E há claramente interesses geopolíticos e econômicos por trás dessa ação estratégica.

Por outro lado, como bem ressalta Umberto Eco, "é por isso que se pode afirmar que a mídia, ao mesmo tempo em que o criticava, atuou como a melhor aliada possível de Bin Laden, que, dessa maneira, venceu a primeira rodada." (Eco, 2001).

Segundo Eco, dado que o objetivo de Bin Laden era criar o maior espetáculo da Terra, deixar uma marca visível de agressão ao poderio ocidental, e mostrar que é possível atingir as sedes do poder norte-americano, ele teve pleno êxito, pois os meios de comunicação foram obrigados a difundir as notícias. Mas, é o que ele se pergunta, será que a mídia precisàva répetir esses relatos diariamente por todo esse tempo? E ele mesmo responde que os jornais aumentaram suas vendas, as emissoras de televisão sua audiência, e assim por diante. Além disso, foi uma forma eficiente de cultivar a indignação e justificar as ações que se sucederam.

Dessa forma, de um lado, tem-se a empresa televisão funcionando como qualquer outra instituição privada de caráter comercial. Sua pauta é a maximização dos lucros; os produtos que oferta ao mercado são as mensagens, os textos-programa. Sob a ótica dessa lógica mercantilista, os textos são mercadorias que, como qualquer outro produto acabado, disputam o mercado global. Interesses e/ou lógicas dessa ordem, definem, entre outras, as estratégias comunicativas da ordem do marketing, adequadas à venda dos produtos, com vistas ao seu consumo. Afinal, a necessidade de aceitação do público e de audiência sustenta a obtenção dos patrocínios que financiam seus produtos. 
Assim, o fato de a televisão ser um negócio, interfere na adoção de determinadas estratégias comunicativas e discursivas, que se expressam de diferentes formas, manifestando-se:

1- no investimento que a emissora se propõe a fazer em determinado programa. Isso implica a análise:

(a) do tipo de inserção do programa na grade de progra mação: periodicidade, dia, horário, duração;

(b) do tipo de custos envolvidos: com atores, cenários, tecnologias;

(c) da quantidade, qualidade e duração das chamadas;

(d) da participação do programa na pauta de outros programas da emissora;

(e) da participação do programa na pauta de outros meios.

2- no tipo de patrocínio escolhido para o programa;

3- no tipo de telespectadores que a emissora projeta como possivel audiência do programa.

Apesar disso, de outro lado, há as lógicas discursivas a que correspondem às estratégias discursivas responsáveis pela articulação do como "dizer"; mas essas, de certa forma, se acomodam e se submetem às lógicas da empresa e do meio. De certa maneira, há uma incidência das estratégias comunicativas sobre as discursivas, tanto as de ordem narrativa como enunciativa. Afinal, toda estruturação narrativa e enunciativa dos textos-programa é planejada considerando: (1) a fragmentação por blocos que os intervalos comerciais impõem; (2) a fragmentação e continuidade que a serialidade requer; (3) a repetição inerente ao fazer parte de uma grade de programação.

A lógica tecnológica, decorrente dos meios técnicos de produção, circulação e consumo dos produtos televisivos, de um lado atua sobre as estratégias comunicativas, de outro, sobre as discursivas, expressando-se: (a) na seleção de determinados programas e matérias para serem exibidas sob a forma de transmissão direta; (b) na 
opção pela compra de imagens de agências de notícia ou pela instituição de correspondentes próprios da emissora; (c) no emprego de técnicas como gravações ao-vivo, transmissões diretas, edição em ilha; (d) na constituição de grupos de experimentação de tecnologias, técnicas e linguagens; (e) na exibição de espetáculos esportivos, artísticos ou na produção de seus próprios programas.

A enunciação é o espaço desencadeador de operações que elegem, dentre as combinatórias de unidades discursivas virtuais, as que estão em condições de produzir os efeitos de sentido desejados. A esse conjunto de deliberações tomadas pela instância de enunciação dá-se o nome de discursivização, e à atualização das escolhas frente ao repertório de possibilidades virtuais. (Greimas, 1998). O termo estratégia, usado nos contextos da guerra e do jogo, aqui interessa se se considerar que todo ato comunicativo é um confronto de quereres e poderes que se submete ao princípio da eficácia. A noção de estratégia contraria o ponto de vista objetivista e determinista do sistema; ela é da ordem prática do uso, não implicando a obediência mecânica a regras explícitas codificadas. Nada simultaneamente mais livre e coagido do que a ação de um bom estrategista. Espaço da liberdade, do à vontade, a estratégia comporta simultaneamente (1) o conhecimento das regras para a elaboração de um programa de ação- seleções, combinações rupturas- que conduza ao êxito; (2) a competência interpretativa da performance do interlocutor, permitindo ao sujeito ir dos atos às intenções do outro de forma a construir uma representação global de seu ser, seu querer e seu possível fazer; (3) a competência manipulatória com vistas a fazer o interlocutor agir no quadro e em proveito do programa de ação por ele estabelecido. (Greimas, 1998)

Projetada essa noção de estratégia no âmbito da produção midiática - comunicação e mercadoria a ser consumida por milhões de receptores - pode-se imaginar o quanto ela deve ser elaborada, calculada, para poder responder às necessidades de economia de tempo da produção e às aspirações de novidade dos espectadores. Há um trabalho criativo de estrategista materializado em cada texto midiático. Trata-se de um projeto concreto que obedece a determinados critérios de seleção e relevância, correspondendo a decisões 
tomadas no processo de produção, responsáveis também pela escolha dos mecanismos de expressão adequados à manifestação dos conteúdos desejados. As estratégias discursivas atualizam-se no texto; não são de outras ordens, não pertencem a outros espaços. Dizem respeito ao modo de contar a narrativa e ao relacionamento dessa com a enunciação.

Assim, como já se ressaltou, pelas características dos processos midiáticos televisivos, seus textos constroem-se na tensão entre diferentes níveis de estratégias que não podem ser confundidas: as estratégias comunicativas são deliberações tomadas em nível de enunciação do processo televisivo, de suas condições de produção, elas podem ou não se manifestarem no texto; já as estratégias discursivas aparecem "com-figuradas" no texto.' A configuração é um procedimento do nível discursivo responsável pela instalação de figuras. As configurações pertencem ao tronco comum semiótico anterior a toda manifestação em uma substância particular de expressão. Mas as figuras materializam-se nos dois planos do texto.

Assim, as estratégias discursivas manifestam-se nos textos através das figuras tanto de conteúdo como de expressão, aqui concebidas como mecanismos expressivos, arranjos de formas de expressão, cuja disposição se submete a regras (sintáticas) de combinação de elementos e de linguagens, selecionados pela instância de produção dentre um repertório de possibilidades virtuais, para manifestar uma determinada figura de conteúdo.

No caso da produção televisiva, um primeiro nível estratégico de caráter discursivo propriamente dito remete à concepção da estrutura geral do texto-programa, à eleição de seu gênero e/ou formato. Segundo Martin-Barbero, as lógicas do sistema produtivo e as lógicas dos usos são mediadas pelos gêneros, cujas regras instituem os diferentes formatos e ancoram o reconhecimento cultural dos sentidos desses produtos pelos grupos. Essa noção de gênero evidente-

1. Hjelmslev emprega o termo figura para designar os não signos, ou seja, as unidades constitutivas do plano de expressāo, ou de conteúdo dos signos. Projetando-se o sentido da palavra figura à análise de um signo de dimensão maior como o texto, podem-se projetar entāo figuras de conteúdo e de expressão como combinatórias de elementos que manifestam a adoção de uma estratégia discursiva. (Hjelmslev, 1975) 
mente tem pouco a ver com a velha noção literária do gênero como "propriedade" de um texto, e menos ainda com a sua redução taxionômica, empreendida pelo estruturalismo. Um gênero não é algo que ocorra no texto, mas sim pelo texto, pois é mais do que uma questão de estruturação, é uma questão de competência. Um gênero é, antes de tudo, uma estratégia de comunicabilidade, e é como marca dessa comunicabilidade que um gênero se faz presente e analisável no texto. É a consideração dos gêneros como fatos puramente "literários" - e não culturais - e sua redução a receitas de fabricação ou a etiquetas de classificação que têm impedido a compreensão de sua verdadeira função e sua pertinência metodológica: a de operar como chave de análise dos textos televisivos.

Pode-se afirmar que o gênero é justamente a unidade mínima do conteúdo da comunicação de massa (pelo menos no nivel da ficção, mas não apenas) e que a demanda de mercados por parte do público (e do meio) aos produtos se faz no nivel do gênero. Para os investigadores, é através da percepção do gênero que se alcança o sentido latente dos textos dos mass media. A dinâmica cultural da televisão atua pelos seus gêneros; que ativam a competência cultural e a seu modo dão conta das diferenças sociais que a atravessam. Os gêneros, que articulam narrativamente as serialidades, constituem uma mediação fundamental entre as lógicas do sistema produtivo $e$ as do sistema de consumo, entre a do formato e a dos modos de ler, dos usos. (Martin-Barbero, 1997, pp. 298 - 9).

Um segundo nível estratégico remete ao enunciador dos textos televisivos.

Não se pode esquecer que a produção televisiva é coletiva. Nessa perspectiva, coloca em questão a noção de autoria exatamente porque os textos televisivos se organizam a partir de diferentes lógicas e pontos de vista.

Por isso, no caso da enunciação televisiva, é tão difícil falar em enunciador: parece haver uma espécie de fuga dos enunciadores 
que se remetem uns aos outros, em termos de concatenações progressivas e culturalmente determinantes, o que resulta num apagamento dos sujeitos nas duas pontas do processo comunicativo. Quem é, por exemplo, o enunciador de um telejornal como o Jornal da Globo, ou de programas como Muvuca, Sai de baixo, ou Progra ma do Jô? Os âncoras, os atores, os entrevistados, os redatores, os câmeras, a cadeia de televisão que os transmite, as forças políticas e/ou econômicas que estão por trás da emissora, a sociedade em geral?... Mesmo a listagem de créditos no final dos programas certamente não esgota o número de sujeitos responsáveis pelo seu processo enunciativo. Embora uma análise mais cuidadosa permita recuperar muitas dessas diferentes logicas que fazem parte das condições específicas de uma produção televisiva, pois elas deixam vestígios nos formatos e modos como a indústria televisiva semantiza e recicla seus produtos, uma das estratégias discursivas empregadas pela tevê é embaralhá-las. Essa confluência de lógicas e vozes cria um efeito de aparente neutralização.

Ao se examinar a grade de programação das emissoras de televisão, constata-se que grande parte dos programas são classificados como informativos: - reportagens, telejornais, entrevistas, talk shows, reality shows, programas de auditório, magazines, etc - remetendo a essa vertente factual ou de "verdade" e "realidade" que vem ganhando cada vez mais espaço na constituição da programação televisiva. Não é objetivo deste trabalho examinar especificidades desses tipologias de gêneros e formatos, mas examinar as diferentes estratégias e figuras empregadas na construção da "informação", de forma a conferir-lhe efeitos de "realidade" e "verdade".

E aqui se apresenta uma terceira questão sobre a qual é interessante refletir: o conceito de informação nesse contexto. Como compreender o que a própria televisão classifica como produtos informativos?

Semioticamente falando, a informação é compreendida com um fazer-saber, oposto ao fazer persuasivo-interpretativo, que, na maioria das vezes, modaliza a informação televisiva. Nessa perspectiva, informação é matéria de atos comunicativos, embora muitas vezes não corresponda às finalidades. A televisão produz sentidos e os oferta à sociedade. Há reciprocidade entre ela e a notícia, pois a tevê, além de construir 
narrativas nas quais se posiciona sobre as coisas do mundo, dá forma a essas declarações que enquadram os acontecimentos numa organização que resulta na construção da notícia. A seleção das informações a serem veiculadas, bem como as formas de estruturação desse material informativo são opções estratégicas que consideram lógicas mercadológicas e discursivas ao determinar o grau de noticiabilidade dessas informações, a sua adequação a certos gêneros e formatos, o seu interesse institucional.

Assim, ganham sentido situações aparentemente contraditórias: mesmo que fazer-saber, em princípio, se oponha a ignorar, é preciso lembrar que os atos comunicativos muitas vezes se utilizam de informações já conhecidas pelos interlocutores, para atender aos seus propósitos. Com isso se quer dizer que, em televisão, informação não é obrigatoriamente sinônimo de novidade; não se contrapõe à desconhecimento, mas constitui-se num procedimento discursivo que se apropria da matéria informativa e a modaliza, submetendo-a às diferentes lógicas que presidem esse tipo de ato comunicativo, com vistas a definir seu tratamento discursivo de forma estratégica e selecionar cuidadosamente as figuras que vão manifestá-las. Dependendo desse tipo de definição, o processo de construção discursiva da informação emprega como estratégia ultrapassar, muitas vezes, os limites de um programa, perpassando a programação em geral e - excedendo a grade de programação da própria emissora e da mídia: seu âmbito é intermidiático. Daí a figura da autoreferenciação: o que caracteriza essa produção televisiva que se apresenta como espetáculo realizado "ao vivo", são seus segmentos autoreferenciais que garantem a articulação básica do relato e sua continuidade, cujo conteúdo e finalidade são a própria existência do meio enquanto mecanismo de produção, circulação e consumo de produtos.

Uma outra estratégia empregada é a fusão de planos e tempos narrativos distintos. Na transmissão do atentado às Torres Gêmeas, por exemplo, ultrapassaram-se não só os limites dos programas, como claramente confundiram-se os planos e tempos do relato e de sua enunciação, que era o tempo dos acontecimentos. Diante do imprevisto dos fatos, o relato, ainda fragmentado e lacunar, apontava um processo enunciativo que buscava se preservar do rumo 
ignorado dos acontecimentos em curso e da produção discursiva que se produzia à sua revelia.

Uma outra estratégia empregada nesse tipo de produção é a recorrência a múltiplas vozes, que se materializam na figura dos entrevistados, especialistas, testemunhas, protagonistas dos fatos etc. Nesse caso, mais do que nas reportagens ao vivo, os telejornais reservam espaços de fala a respeito dos eventos, que são ocupados por diferentes sujeitos falantes se sucedem, que se revezam, se contrapõem uns aos outros, cada um deles afirmando a sua versão dos fatos relatados e todos, no conjunto, construindo a versão da emissora. Assim, os diferentes tipos de depoimentos são uma estratégia utilizada não só para conferir efeitos de credibilidade e confiabilidade à televisão fundadas na objetividade e imparcialidade. Se os modelos tradicionais de telejornalismo prezam a imparcialidade, impedindo com isso, apresentadores e repórteres de dizerem o que pensam, esse não é o caso dos entrevistados e das testemunhas oculares dos fatos, tampouco dos especialistas, cuja função é dotar os acontecimentos de sentidos.

Aliás, os telejornais da Globo News mostram isso normalmente. Mas essa estratégia, baseada muito mais na apresentação de depoimentos dos sujeitos implicados no acontecimento, no caso Afeganistão, teve que ser substituída, pois os protagonistas dos acontecimentos, ou aqueles que o testemunharam, não podiam ser ouvidos. Por isso, a tevê obrigou-se a recorrer ao testemunho indireto dos enviados da própria emissora para reportar o evento.

Mesmo com repórteres e apresentadores tentando ser objetivos, neutros, ou imparciais, essa construção de um macro ponto de vista que, às vezes, perpassa toda a programação de uma emissora e de outras, tem um caráter intermidiático, acontecendo devido a interesses e lógicas que são colocados em jogo pela produção televisiva. O objeto da informação, vide Torres Gêmeas, é aniquilado pelas suas versões; delas restam apenas pontos de vista: a televisão assume o espaço estratégico de geradora do acontecimento que vira discurso.

Todo esse processo estratégico indica um percurso a ser percorrido pelo telespectador de construção dos sentidos dos fatos. 
No caso do atentado de 11 de setembro, os fatos recortados pelas câmeras passaram rapidamente por diferentes interpretações que foram se sucedendo: ao acidente, correspondeu o choque na $1^{a}$ Torre; ao atentado, correspondeu o choque na $2^{\mathrm{a}}$ Torre; ao ato terrorista islâmico, correspondeu a descoberta de que havia passageiros árabes etc... Esses diferentes sentidos ainda hoje estão em processo de articulação. Embora dispersos e, às vezes, contraditórios, eles acabam por participar da construção de uma única e consistente versão dos fatos: aquela que responde às lógicas e interesses da emissora e, muitas vezes, da mídia global, como aconteceu no caso do ataque às Torres Gêmeas. Por isso, a isenção é aparente. Figuras como o embaralhamento de fontes diversas, a apresentação de razões dos dois lados dos conflitos, a recorrência à opinião de especialistas, embora se constituam em fragmentos de uma ação democrática e imparcial, perdem sua autonomia no fluxo televisual que as articula $e$ ordena a partir de pontos de vista definidos, com vistas a fornecer uma única visão dos fatos.

Alguns formatos menos tradicionais do gênero informativo incorporam recursos narrativos da ficção audiovisual com o mesmo propósito. Esse é o caso de programas, como Linha Direta, que recorrem a depoimentos, trilhas sonoras, encenação dos acontecimentos com os atores. Com esses recursos retóricos, abre-se espaço para a manifestação de posicionamentos, emoções e indignações frente aos pretensos fatos. E, muitas vezes, passa-se da assistência à ação.

Uma outra estratégia discursiva empregada cada vez mais freqüentemente nesse tipo de produto televisivo é a pretensa exibição de seu processo de produção, introduzindo no interior do textoprograma a figura que muitos denominam de enunciação-enuncia$d a$. É como se o texto se oferecesse diretamente ao leitor em sua textualidade e textualização, e, com isso, pudesse controlar sua leitura. Mas, na verdade, como em todo processo sígnico, o que essa estratégia constrói são apenas efeitos de realidade, de verdade, de "aqui e agora", de "ao vivo", apesar de muitos desses programas serem pré-gravados e cuidadosamente editados.

Aliás, o programa Sai de baixo faz humor escrachado sobre essa estratégia. Em todos os seus episódios, faz menção ao seu 
processo de produção: o programa é gravado ao vivo com presença da platéia, os atores não disfarçam quando esquecem suas falas, mas, no final, depois dos créditos, aparecem as cenas excluídas pelos erros, pelos lapsos de memória dos atores, pelos ataques de riso de que são acometidos, e que foram cortados na edição do programa. Por isso, é preciso que se diga, nesses casos, está-se frente a um texto televisivo que, através de efeitos discursivos, constrói um simulacro de enunciação: curiosamente, nesse exemplo, trata-se de uma enunciação enunciada de um texto que se assume como ficção. Mas a figura pode ser vista nos telejornais, nos programas de entrevista etc.

Como uma outra estratégia empregadas pela televisão aberta é a unificação de uma "fala" homogênea com vistas à constituição de um só público, reduzindo ou absorvendo com isso as diferenças, a veiculação dessa macro versão dos fatos, aquela que causa menor choque aos valores e preconceitos da maioria, acaba por se impor.

Assim, a subjetividade das vozes individuais, públicas ou privadas, que povoam o universo da informação televisiva, vale como moeda de troca, conferindo credibilidade a essa realidade/ artificialidade que a tevê constrói. Atualmente, à televisão se atribui mesmo uma competência institucional que lhe permite passar da comunicação à ação, isto é, transformar sua dimensão semiótica em pragmática.

Dessa forma, nesse grande cenário narrativo, a informação intercambia seus signos com os da ficção, o real se confunde com o imaginário e os signos não mais dissimulam sua não coincidência com a realidade; disfarçam, isto sim, a sua dissuasão. Em outros termos, há uma evidente substituição de uma teologia da verdade e do segredo, da realidade e da ficção, pela da realidade e da artificialidade. E a estratégia empregada para sustentar essa segunda natureza é a construção de um mundo inteiramente autoreferencial que ainda se dá ao "luxo" de importar os fragmentos da "realidade real" que lhe é paralela como artifício retórico para criar efeitos de "realidade" e "naturalidade".

Se a linguagem já havia roubado o acesso direto ao mundo natural, à realidade - hoje, perdida a natureza, a mídia oferece uma 
segunda natureza, uma segunda pele siliconada, vitaminada, construída no espaço de interação entre os diferentes mídias. O mundo artificial em que vivemos é o verdadeiro, embora artificial E a autoreferencialidade, responsável pela artificialidade-verdade dos fatos midiáticos estrutura-se na inter-relação das diferentes mídias, tendo por cúmplice as linguagens: a verdade, antes referenciada pela correlação tempo-espaço, passa a ser medida pela auto, co e interreferencialidade das mídias. Voz das mídias, voz de Deus.

Assim, o analista deve ter presente que os textos televisivos são produzidos em um espaço - o midiático - cuja atualização se faz necessária à interpretação dos sentidos e cujos limites muitas vezes não são facilmente definíveis: cada caso é um caso. Dependendo do que se pretenda analisar, pode ou não haver necessidade de recorrência à enunciação e, quando isso acontece, muitas vezes se precisa atualizar apenas alguns elementos desse processo -, aqueles pertinentes à análise empreendida. Dito de outra forma, devido à complexidade dos processos midiáticos televisivos, não se pode pretender dar conta de todos os aspectos envolvidos na produção dos textos midiáticos. Por isso, como, em cada análise, a proposta é examinar determinados elementos, esses é que devem definir que aspectos e instâncias do processo midiático devem ser atualizados para que se possam alcançar os objetivos perseguidos.

\section{Bibliografia}

BARTHES, Roland. 1982. Mitologias. São Paulo: Difel.

BUONANNO, Milly. 1999. El drama televisivo: identidad y contenidos sociales. Barcelona: Gedisa.

CALABRESE, O. 1989. A idade neobarroca. Lisboa: 7.

1995. La informacion y el espectador. Um juego de pasiones. In: . Los juegos de la imagem. Bogotá: Instituto Italiano de Cultura. 
CASETTI, Francesco; CHIO, Federico di. 1999. Análisis de la televisión: instrumentos, métodos y prácticas de investigación. Barcelona: Paidós.

ECO, U. 1984. Conceito de texto. São Paulo: USP.

. 2001. "Mídia foi o melhor aliado de Bin Laden". Folha de São Paulo. São Paulo, 2 dez., p. A25.

FABRI, P. 2000. El giro semiótico. Barcelona: Gedisa.

GARDIES, René; TARANGER, Marie-Claude. 2001. Télévision: questions de formes. Paris: L'Harmattan.

GRANDI, R. 1995. Texto y contexto en los medios de comunicaión. Barcelona: Bosch.

GREIMAS, A. J. 1998. A propósito do jogo. Verso e Reverso. São Leopoldo, 27 (12).

HJELMSLEV, Louis. 1975. Prolegômenos a uma teoria da linguagem. São Paulo: Perspectiva.

JOST, François. 2001. La televisión du quotidien: entre réalité et fiction. Bruxelas: De Boeck Université.

LACALLE, Maria R. 1995. La voz del espectador. Telos, 43.

LAMBERT, Frédéric. 2001. Figures de l'anonymat: médias e société. Paris: L'Harmattan.

MACHADO, Arlindo. 2000. A televisão levada a sério. São Paulo: SENAC.

MARTIN-BARBERO, Jesús. 1997. Dos meios às mediações: comunicação, cultura e hegemonia. Rio de Janeiro: UFRJ.

REQUENA, Jesus Gonzales. 1999. El discurso televisivo: espectáculo de la posmodernidad. 4.ed. Madrid: Cátedra.

SUBIRATS, Eduardo. 1998. A cultura como espetáculo. São Paulo: Studo Nobel.

VERON, E. 1997. La semiosis social. Barcelona: Gedisa.

ZALDUENDO, Charo Lacalle. (1999). Mitologías cotidianas y pequeños rituales televisivos: los talk shows. Madrid: Gedisa. 